trial). Furthermore, it is not clear how useful they would be to treat a completely new virus or how great the risks from resistant strains would be.

Neuraminidase inhibitor antiviral drugs are licensed for prophylaxis in high risk groups (as recommended by the National Institute for Health and Clinical Excellence). However, prescribing them for prophylaxis in a pandemic might be an extravagant use of limited resources. This could be justified only if there were good grounds to think a vaccine was imminent. It might be preferable to institute early treatment rather than offer prophylaxis, because the stimulus of infection will prompt an antibody response.

\section{Supply shortages}

Vaccines and drugs will be manufactured at selected plants. In the event of a serious pandemic, countries may suspend routine trading practices. Governments will be strongly tempted to suspend the export of drugs in short supply, and in some countries there may be no local manufacturer and no drugs or vaccines available. There is clearly an ethical dilemma between the competing interests of countries with manufacturing capacity and those without. An ethical dilemma also exists with respect to people in countries with inadequate resources to meet the cost of vaccines and drugs.

Should a pandemic emerge within 12 months, the availability of antiviral drugs will be limited, and people at high risk will need to be given priority; the groups at risk may differ from those conventionally associated with the routine annual vaccination programme. Healthcare workers and people operating essential services might be the most important groups to protect. Serious illness in children might result in redefining the concept of risk.

\section{Summary points}

Now is the time for general practices to plan their response to managing a pandemic

Engage your entire practice team in those discussions

Familiarity with the national plan and cooperation in it are essential

Be prepared for an illness in which the principles of prioritisation of treatment groups will be needed

Improve your capacity to manage illness on the basis of telephone contact

Obtain and provide accurate information: do not be swayed by media hype

The author is also director of the Birmingham Research Unit of the Royal College of General Practitioners. The unit is funded by the Department of Health and is particularly concerned with routine surveillance of common diseases presenting in primary care. The contents and opinions expressed in this article are exclusively those of the author.

Competing interests: The author has provided consultancy services to several pharmaceutical companies engaged in drug and vaccine manufacture of flu related products.

1 Department of Health. UK health departments' influenza pandemic contingency plan. London: DoH, 2005 (October). (www.dh.gov.uk, search with ref 4615).

\section{Hide the title}

As anybody knows who has sat on an interview panel, people choose a career in medicine for different reasons-interests, steady job, tradition-but if you speak in depth to most medics we all feel that we are "doing our bit." Working as hard as we do to help others is the crux of our career choice and, in spite of all the surrounding difficulties, is the main joy of being a doctor. Now for this we get reasonable remuneration and hopefully some degree of job satisfaction. Do other members of the public see us in this light, or are we seen as fat cats and fair game because of the image of the rich doctor on the golf course?

My wife and I recently moved house and, because of several incidents, decided to use this (unpleasant) experience to see how your average workman reacted to us being a couple who both happen to be doctors. Our "hypothesis" was a rather cynical one-that people who knew of our profession were apt to change their quotes accordingly. The house we moved to is in a fairly affluent area of Cheshire with a semi-professional population-we have several medical colleagues living in the same postcode.

We chose four jobs to be quoted for-removal expenses, fitting the house with a burglar alarm, garden fencing, and an extra television aerial to be fitted in the bedroom. For each job, we got three quotes from firms advertising in the local telephone book. For two of these quotes we were simply Mr and Mrs, but for the third we introduced ourselves as Dr.

The results spoke for themselves. Of those companies who knew we were doctors, the removals company quoted in excess of $£ 250$ more than the other two companies, the garden fencing was about $£ 200$ more expensive, and the aerial doubled in price. Our only piece of good news was the alarm company, which turned out to be the cheapest of the three (name supplied on request) and which was promptly hired.

This is something I have long wondered about, but have been told that I am a cynical old man (at 29) and that the British public should be trusted. I would just like to point out that, even though we gain satisfaction from helping our fellow humans at work, after having trained for many years, the fact that we are doctors means to some that we are targets for inflated costs. I for one am now going to keep my job under wraps and use any money I save to put myself through a DIY course.

Jon Durnian specialist registrar in ophthalmology, Royal Liverpool Hospital,Liverpool (jon_durnian@hotmail.com)

Competing interests: My wife and I have a definite, significant financial interest in this study. 